\title{
Performance of Air-Cooled Heat Exchanger with Laminar, Transitional, and Turbulent Tube Flow
}

\author{
Dawid Taler* \\ Cracow University of Technology, Faculty of Environmental Engineering, Department of Thermal Processes, Air Protection and \\ Waste Utilization, 31-155 Cracow, Poland
}

\begin{abstract}
Some air-cooled heat exchangers, especially in air conditioning and heating installations, heat pumps, as well as car radiators, work in a wide range of loads when the liquid flow in the tubes can be laminar, transitional or turbulent. In this paper, a semi-empirical and empirical relationship for the Nusselt number on the liquid-side in the transitional and turbulent range was derived. The friction factor in the transition flow range $\operatorname{Re}_{\mathrm{w}, \mathrm{rrb}} \leq \mathrm{Re}_{\mathrm{w}} \leq \mathrm{Re}_{\mathrm{w} \text {,tre }}$ was calculated by linear interpolation between the values of the friction factor for $\mathrm{Re}_{\mathrm{w}, \mathrm{trb}}=2,100$ and $\mathrm{Re}_{\mathrm{w}, \mathrm{tre}}=3,000$. Based on experimental data for a car radiator, empirical heat transfer relationships for the air and water-side were found by using the least squares method. The water temperature at the outlet of the heat exchanger was calculated using P-NTU (effectivenessnumber of transfer units) method. The heat flow rate from water to air was calculated as a function of the water flow rate to compare it with the experimental results. The theoretical and empirical correlation for the water-side Nusselt number developed in the paper were used when determining the heat flow rate. The calculation results agree very well with the results of the measurements.
\end{abstract}

\section{Introduction}

Heat transfer correlations for calculating heat transfer coefficients on both air and water side are needed in the thermal calculations of heat exchangers using engineering methods such as LMTD, $\varepsilon$-NTU, and PNTU [1-4]. Turbulent flow regime of the fluid in tubes is usually assumed in the design and performance calculations of the plate fin and tube heat exchangers (PFTHEs). Usually, the power-type heat transfer correlations are applied for calculating the water and airside heat transfer coefficients [1-6]. The most popular heat transfer correlations on the water-side are the wellknown relationships of Dittus-Boelter and Sieder and Tate. The Gnielinski [7] relationship is also frequently used. These correlations are appropriate only for high Reynolds numbers when the $\mathrm{Re}_{\mathrm{w}}$ is larger than 4000 . Recently, Taler [8-9] proposed a new correlation to calculate the Nusselt number for the transitional and turbulent fluid flow inside the tubes at a given tube surface temperature or constant heat flux. In this paper, theoretical and empirical relationships were found. The tube-side heat transfer correlations proposed in [8, 9] were generalized to account that transitional flow begins at $\operatorname{Re}_{w, \text { trb }}$ and ends at $\operatorname{Re}_{w, \text { tre. }}$ It was assumed in $[8,9]$ that $\operatorname{Re}_{w, \text { trb }}=2300$ and $\operatorname{Re}_{w, \text { tre }}=3000$. However, the experimental results obtained by Ghajar et al. [10] and Meyer and co-workers [11] showed that the values of $\mathrm{Re}_{w, \text { trb }}$ and $\mathrm{Re}_{w, \text { tre }}$ can differ from the values 2300 and 3000 , respectively. Air and water-side heat transfer correlations for a PFTHE made of circular tubes were determined by the least squares method using 70 experimental data sets obtained in transitional and turbulent flow regime. To calculate the air and water temperature at the outlet of the heat exchanger, the PNTU method was used. Empirical water and air side correlations were determined based on 70 measurement series including transitional and turbulent flow regimes. Experimental tests were carried out on the new-design car radiator made of circular tubes. The water-side friction factor was linearly interpolated between $\xi_{w}=$ 64/ $\mathrm{Re}_{w}$ for laminar flow at $\mathrm{Re}_{w}=\mathrm{Re}_{w, \text { trb }}$ and the friction factor for the turbulent flow $\xi_{w}\left(\operatorname{Re}_{w, \text { trb }}\right)$ both in a theoretical and empirical relationship for the Nusselt number. The water-side friction factor in the turbulent flow regime, when the Reynolds number is higher than $\mathrm{Re}_{w, \text { trb }}$ was determined using explicit formula recently proposed by Taler [12]. The Gnielinski formulas [7] was used to calculate the heat transfer coefficient for the laminar flow of the liquid in heat exchanger tubes. The heat flow rate transferred in the studied heat exchanger from the hot water to the air was calculated by the PNTU method in which new heat transfer correlations were used. It was shown that computed and experimentally determined heat flow rates are in good agreement.

\footnotetext{
Corresponding author: dtaler@pk.edu.pl
} 


\section{Performance calculations of the investigated PFTHE}

Performance calculations of the investigated PFTHE, i.e., determining the temperature of the water and air at the outlets of the investigated heat exchanger was conducted using the P-NTU method.

a)
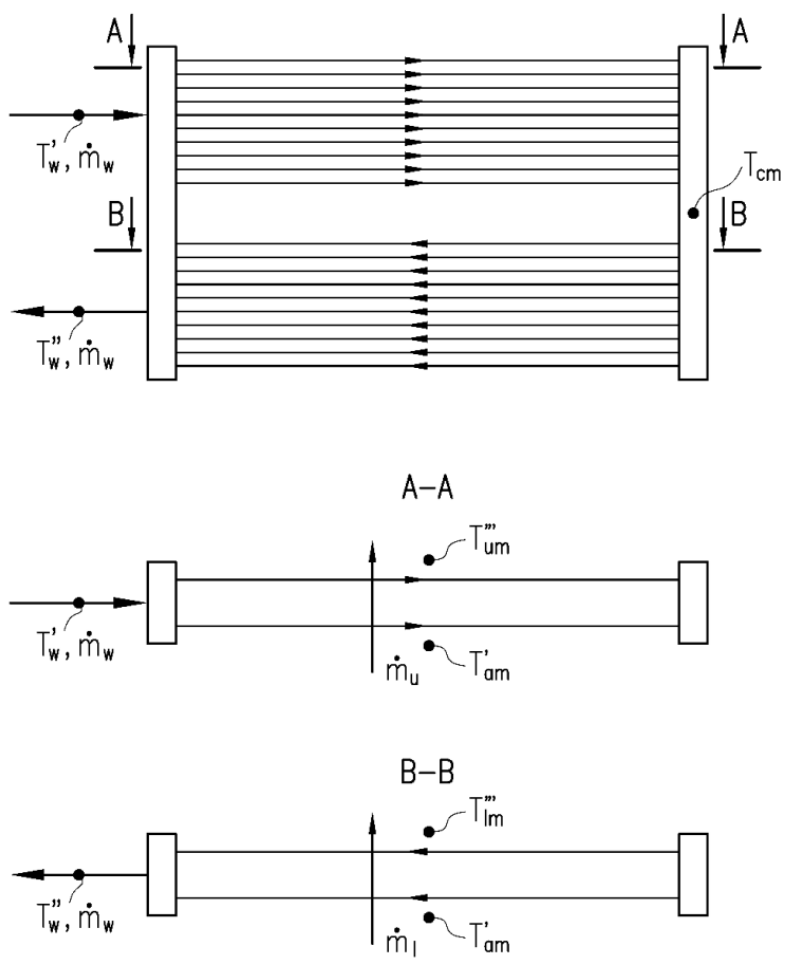

b)

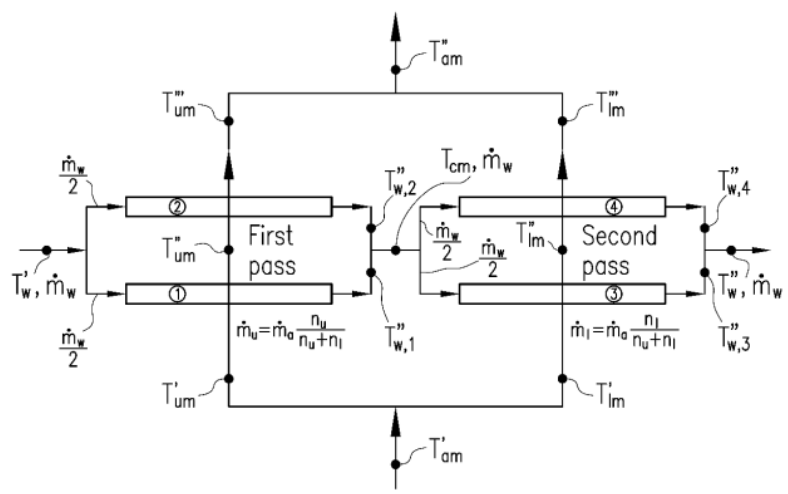

Fig. 1. Flow arrangement of the two-row car radiator with two passes; a) front and top view, b) flow system; 1 - the first tube row in the first (upper) pass, 2 - the second tube row in the first (upper) pass; 3 - the first tube row in the second (lower) pass, 4 - the second tube row in the the second (lower) pass.

Thermo-hydraulic tests of air-cooled plate fin-andtube heat exchanger were carried out in a laminar, transition and turbulent flow regime of water in the tubes. The tested PFTHE was a car radiator for a spark engine with a displacement volume of $1,600 \mathrm{~cm}^{3}$. Two- pass car radiator has two rows of round tubes. There are twenty tubes in the first pass, ten in each row, i.e. $n_{u}=$ 10. The number of tubes in the second pass is smaller and is eighteen, nine in each row, i.e. $n_{l}=9$. The tube arrangement is in-line. Water flows in parallel through the first and second row of tubes in both first and second pass. Between the first and second pass, there is a chamber in which water from the first and second row of tubes is mixed and then flows into the second pass. The flow arrangement of an automobile radiator is shown in Fig. 1. The internal diameter of the tube with the wall thickness $\delta_{t}=0.5 \mathrm{~mm}$ is $d_{i n}=6.2 \mathrm{~mm}$. The transverse pitch of the tube arrangement is equal to $p_{1}=18.5 \mathrm{~mm}$, and the longitudinal pitch is $p_{2}=10 \mathrm{~mm}$. The plate fins with a thickness of $0.08 \mathrm{~mm}$ are set on tubes with the pitch of $1.5 \mathrm{~mm}$. Dimensions of the heat exchanger are as follows: length $L_{c h}=520 \mathrm{~mm}$, height $\mathrm{H} L_{c h}=359 \mathrm{~mm}$, and thickness $W_{c h}=2 p_{2}=24 \mathrm{~mm}$. The mean water $T_{c m}$ and air temperature $T_{u m}^{\prime \prime \prime}$ after the first pass and after the second pass $T_{w}^{\prime \prime}$ and $T_{l m}^{\prime \prime \prime}$ (Fig. 1) were calculated using the P-NTU (Effectiveness - Number of Transfer Units) method.

The mean water $T_{c m}$ and air temperature $T_{u m}^{\prime \prime \prime}$ after the first pass and after the second pass $T_{w}^{\prime \prime}$ and $T_{l m}^{\prime \prime \prime}$ (Fig. 1) were calculated using the P-NTU (Effectiveness Number of Transfer Units) method.

Formulas for calculating the water-side effectiveness $P_{w}$ and air-side effectiveness $P_{a}$ were derived based on the mathematical model of the heat exchanger developed by Taler [13].

The numbers of heat transfer units for water $\mathrm{NTU}_{w}$ and air $\mathrm{NTU}_{a}$ are defined in relation to one tube located in the first (upper) or second (lower) pass. The numbers of transfer units are as follows

- $\quad$ first (upper) pass

- $\quad$ second (lower) pass

$$
N_{a, u}=\frac{U_{o, u} A_{o}}{\dot{m}_{a, t} \bar{c}_{p, a}}, \quad N_{w, u}=\frac{U_{o, u} A_{o}}{\dot{m}_{w, t}^{u} \bar{c}_{p, w}}
$$

$$
N_{a, l}=\frac{U_{o, l} A_{o}}{\dot{m}_{a, t} \bar{c}_{p, a}} \quad N_{w, l}=\frac{U_{o, l} A_{o}}{\dot{m}_{w, t}^{l} \bar{c}_{p, w}}
$$

The mass flow rate $\dot{m}_{a, t}=w_{0} p_{2} L_{c h} \rho_{a}\left(T_{a m}^{\prime}\right)$ in Eq. (1) and (2) denotes the air mass flow rate per one pitch $p_{2}$ (through the cross-section $\mathrm{p}_{2} L_{c h}$ ). Similarly, the water mass flow rates $\dot{m}_{w, t}^{u}$ and $\dot{m}_{w, t}^{l}$ per one tube are $\dot{m}_{w, t}^{u}=\frac{\dot{m}_{w}}{2 n_{u}}$ and $\dot{m}_{w, t}^{l}=\frac{\dot{m}_{w}}{2 n_{l}}$, respectively.

The numbers of heat transfer units in the first pass for air and water are defined by

$$
P_{a, u}=\frac{T_{u m}^{\prime \prime \prime}-T_{a m}^{\prime}}{T_{w}^{\prime}-T_{a m}^{\prime}} \quad P_{w, u}=\frac{T_{c m}-T_{w}^{\prime}}{T_{w}^{\prime}-T_{a m}^{\prime}}
$$

The following formulas were obtained using the mathematical model of the exchanger presented in the paper [13] 


$$
\begin{aligned}
& P_{a, u}=\left(1-e^{-N_{a, u}}\right)^{2}\left(\frac{1-e^{-B_{u}}}{B_{u}}-e^{-B_{u}}\right)+ \\
& +\left(1-e^{-2 N_{a, u}}\right) \frac{1-e^{-B_{u}}}{B_{u}} \\
& P_{w, u}=1-e^{-B_{u}}-\frac{N_{w, u}}{2 N_{a, u}}\left(1-e^{-N_{a, u}}\right)^{2} e^{-B_{u}}
\end{aligned}
$$

where the symbol $B_{u}$ denotes

$$
B_{u}=\frac{N_{w, u}}{N_{a, u}}\left(1-e^{-N_{a, u}}\right)
$$

The water temperature $T_{c m}$ at the outlet from the first pass as well as the average air temperature $T_{u m}^{\prime \prime \prime}$ after the first pass can be determined using only the formula (5) for water-side effectiveness $P_{w, u}$. The temperature $T_{c m}$ can be obtained from the definition (3)

$$
T_{c m}=T_{w}^{\prime}-P_{w, u}\left(T_{w}^{\prime}-T_{a m}^{\prime}\right)
$$

where $P_{w, u}$ is calculated using the relationship (5).

Solving the heat balance equation for the upper pass

$$
\dot{m}_{w} \bar{c}_{w}\left(T_{w}^{\prime}-T_{c m}\right)=\dot{m}_{u} \bar{c}_{p, a}\left(T_{u m}^{\prime \prime \prime}-T_{a m}^{\prime}\right)
$$

gives the air temperature $T_{u m}^{\prime \prime \prime}$

$$
T_{u m}^{\prime \prime \prime}=T_{a m}^{\prime}+\frac{\dot{m}_{w} \bar{c}_{w}}{\dot{m}_{u} \bar{c}_{p, a}}\left(T_{w}^{\prime}-T_{c m}\right)
$$

The air mass flow rate $\dot{m}_{u}$ through the upper heat exchanger pass is

$$
\dot{m}_{u}=\dot{m}_{a} \frac{n_{u}}{n_{u}+n_{l}}
$$

With the known temperature $T_{c m}$, the liquid temperature $T_{w}^{\prime \prime}$ at the heat exchanger outlet and the air mean temperature $T_{l m}^{\prime \prime \prime}$ behind the second pass can be determined similarly. The air-side and water sideeffectiveness of the second pass is defined as

$$
P_{a, l}=\frac{T_{l m}^{\prime \prime \prime}-T_{a m}^{\prime}}{T_{c m}-T_{a m}^{\prime}} \quad P_{w, l}=\frac{T_{c m}-T_{w}^{\prime \prime}}{T_{c m}-T_{a m}^{\prime}}
$$

The relationships for $P_{a, l}$ and $P_{w, l}$ are as follows

$$
\begin{aligned}
& P_{a, l}=\left(1-e^{-N_{a, l}}\right)^{2}\left(\frac{1-e^{-B_{l}}}{B_{l}}-e^{-B_{l}}\right)+ \\
& +\left(1-e^{-2 N_{a, l}}\right) \frac{1-e^{-B_{l}}}{B_{l}} \\
& P_{w, l}=1-e^{-B_{l}}-\frac{N_{w, l}}{2 N_{a, l}}\left(1-e^{-N_{a, l}}\right)^{2} e^{-B_{l}}
\end{aligned}
$$

where the symbol $B_{l}$ denotes

$$
B_{l}=\frac{N_{w, l}}{N_{a, l}}\left(1-e^{-N_{a, l}}\right)
$$

The water temperature $T_{w}^{\prime \prime}$ at the outlet from the second pass and the average air temperature $T_{l m}^{\prime \prime \prime}$ after the second pass can be determined using the relationships (11) for the air-side effectiveness $P_{a, l}$ and water-side effectiveness $P_{w, l}$. The water temperature $T_{w}^{\prime \prime}$ at the outlet from the second pass is

$$
T_{w}^{\prime \prime}=T_{c m}-P_{w, l}\left(T_{c m}-T_{a m}^{\prime}\right)
$$

where $P_{w, l}$ is given by Eq. (13).

Solving the heat balance equation for the second pass

$$
\dot{m}_{w} \bar{c}_{w}\left(T_{c m}-T_{w}^{\prime \prime}\right)=\dot{m}_{l} \bar{c}_{p, a}\left(T_{u l}^{\prime \prime \prime}-T_{a m}^{\prime}\right)
$$

gives the mean air temperature $T_{l m}^{\prime \prime \prime}$ after the second pass

$$
T_{l m}^{\prime \prime \prime}=T_{a m}^{\prime}+\frac{\dot{m}_{w} \bar{c}_{w}}{\dot{m}_{l} \bar{c}_{p, a}}\left(T_{c m}-T_{w}^{\prime \prime}\right)
$$

The air mass flow rate $\dot{m}_{l}$ through the lower (second) heat exchanger pass is

$$
\dot{m}_{l}=\dot{m}_{a} \frac{n_{l}}{n_{u}+n_{l}}
$$

The mean temperature of the air $T_{a m}^{\prime \prime}$ after the heat exchanger is calculated from the formula

$$
T_{a m}^{\prime \prime}=\frac{n_{u}}{n_{u}+n_{l}} T_{u m}^{\prime \prime \prime}+\frac{n_{l}}{n_{u}+n_{l}} T_{l m}^{\prime \prime \prime}
$$

If the temperature of the water $T_{w}^{\prime \prime}$ at the exit from the heat exchanger is known, then the temperature of the air after the heat exchanger $T_{a m}^{\prime \prime}$ can also be determined from the heat balance equation for the exchanger (Fig. 1)

$$
\dot{m}_{w} \bar{c}_{w}\left(T_{w}^{\prime}-T_{w}^{\prime \prime}\right)=\dot{m}_{a} \bar{c}_{p a}\left(T_{a m}^{\prime \prime}-T_{a m}^{\prime}\right)
$$

Solving Eq. (20) for $T_{a m}^{\prime \prime}$ gives

$$
T_{a m}^{\prime \prime}=T_{a m}^{\prime}+\frac{\dot{m}_{w} \bar{c}_{w}}{\dot{m}_{a} \bar{c}_{p a}}\left(T_{w}^{\prime}-T_{w}^{\prime \prime}\right)
$$

The presented procedure for calculating the water and air outlet temperature based on the P-NTU method can also be applied to other types of heat exchangers with different flow systems. Many relationships for calculating the effectiveness $P$ as a function of the number of transfer units NTU can be found in the books on the heat exchangers [1-4].

Overall heat transfer coefficients $h_{o, l}$ and $h_{o, u}$ referred to the outer surface area of the bare tube for the lower and upper pass are given by

$$
\begin{aligned}
& \frac{1}{U_{o, l}}=\frac{1}{h_{w, l}} \frac{r_{o}}{r_{i n}}+\frac{r_{o}}{k_{t}} \ln \left(\frac{r_{o}}{r_{i n}}\right)+\frac{1}{h_{o}} \\
& \frac{1}{U_{o, u}}=\frac{1}{h_{w, u}} \frac{r_{o}}{r_{i n}}+\frac{r_{o}}{k_{t}} \ln \left(\frac{r_{o}}{r_{i n}}\right)+\frac{1}{h_{o}}
\end{aligned}
$$

The effective heat transfer coefficient $h_{o}$ taking into account the presence of fins, based on the surface area of the bare tube was determined using the following relationship

$$
h_{o}=\left(\frac{A_{b f}}{A_{o}}+\frac{A_{f}}{A_{o}} \eta_{f}\right) h_{a}
$$

The continuous fin was divided into 38 rectangular fins due to the symmetry of the temperature field in the continuous fin. The fin efficiency $\eta_{f}$ was determined assuming that the air-side heat transfer coefficient $h_{a}$ is constant. With this assumption, the fin efficiency $\eta_{f}$ can be determined using the formula

$$
\eta_{f}=\frac{\bar{T}_{f i n}-T_{f}}{T_{b}-T_{f}}
$$


where $\bar{T}_{f i n}$ is the mean temperature of the fin surface.

The surface temperature of the fin $T_{f i n}$ and the average surface temperature of the $\bar{T}_{\text {fin }}$ were calculated by the finite element method (FEM) using the software ANSYS v.16. The thermal conductivity of the aluminum fin was $k_{\text {fin }}=207 \mathrm{~W} /\left(\mathrm{m}^{2} \cdot \mathrm{K}\right)$. The calculations were carried out for the air-side heat transfer coefficient $h_{a}$ varying from $5 \mathrm{~W} /\left(\mathrm{m}^{2} \cdot \mathrm{K}\right)$ to $300 \mathrm{~W} /\left(\mathrm{m}^{2} \mathrm{~K}\right)$ with a 5 $\mathrm{W} /\left(\mathrm{m}^{2} \mathrm{~K}\right)$ step. The temperature of the fin base $T_{b}$ was assumed to be $100^{\circ} \mathrm{C}$. Temperature distributions on the fin surface for heat transfer coefficients of 5, 50, 100 and $300 \mathrm{~W} /\left(\mathrm{m}^{2} \cdot \mathrm{K}\right)$ are depicted in Fig. 2. The analysis of the results presented in Figure 3 shows that the temperature of the fin decreases with the increase in the air-side heat transfer coefficient $h_{a}$. The calculated fin efficiencies $\eta_{f}$ for different heat transfer coefficients $h_{a}$ using the ANSYS 16 were approximated using the least squares method.
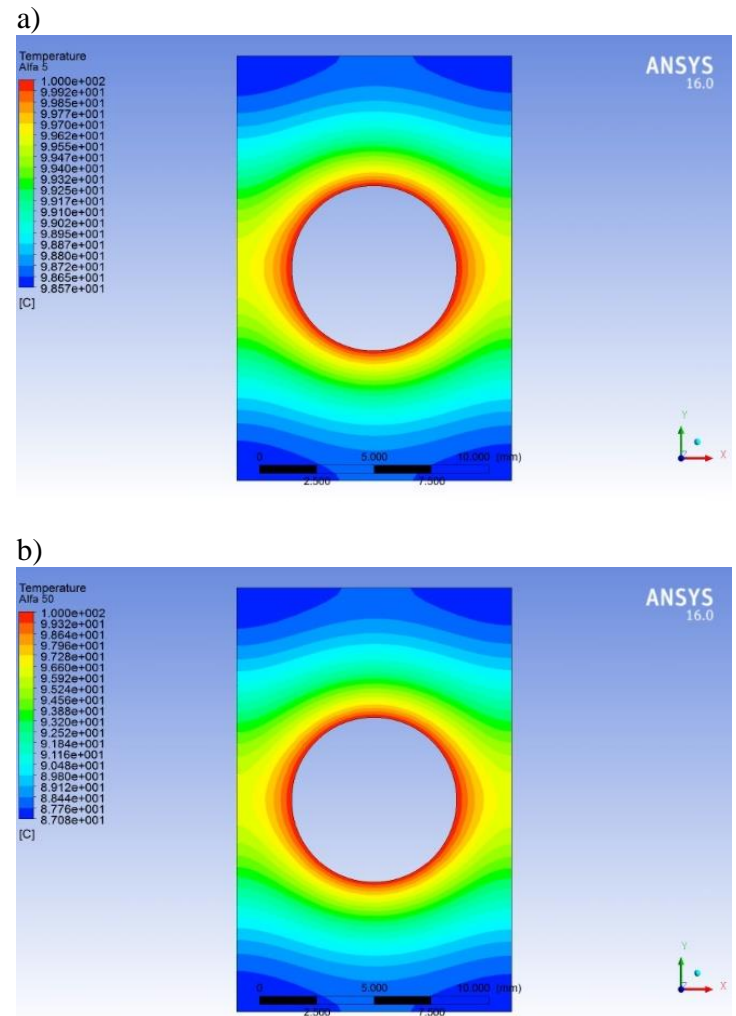

c)

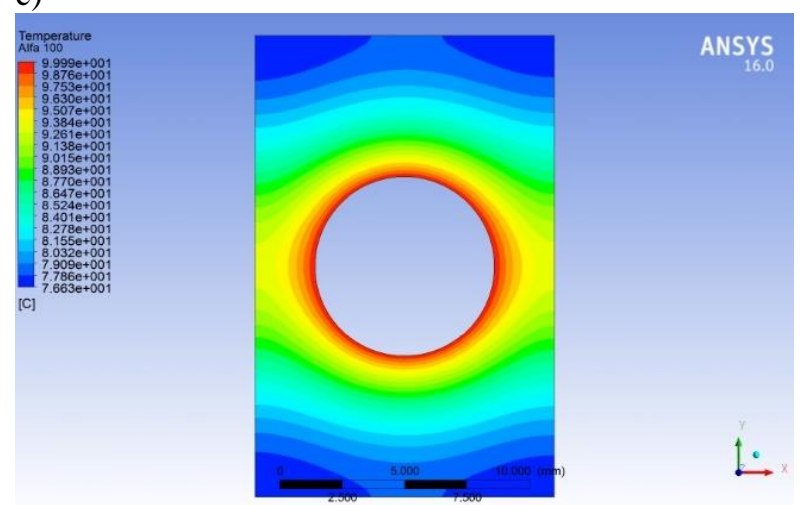

d)

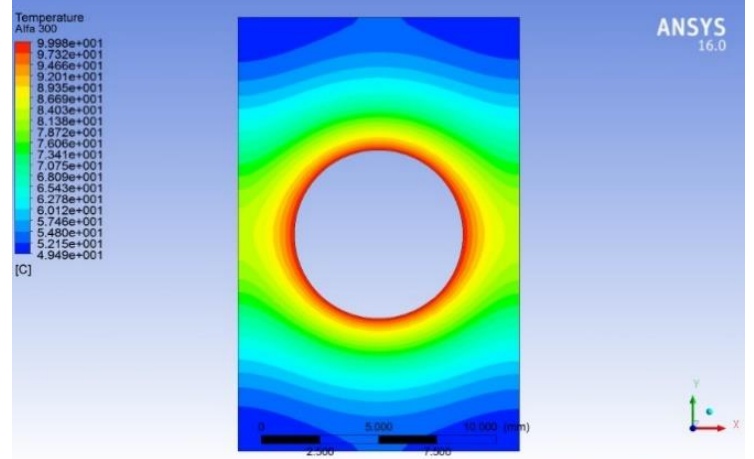

Fig. 2. Temperature distributions on the fin surface for various heat transfer coefficients; a) $h_{a}=5 \mathrm{~W} /\left(\mathrm{m}^{2} \cdot \mathrm{K}\right)$, b) $h_{a}=50$ $\mathrm{W} /\left(\mathrm{m}^{2} \cdot \mathrm{K}\right)$, c) $\left.h_{a}=100 \mathrm{~W} /\left(\mathrm{m}^{2} \cdot \mathrm{K}\right), \mathrm{d}\right) h_{a}=300 \mathrm{~W} /\left(\mathrm{m}^{2} \cdot \mathrm{K}\right)$.

The function

$$
\begin{aligned}
& \eta_{f}=\frac{0.999882+0.0003515 h_{a}}{1+0.0021342 h_{a}} \\
& 0 \leq h_{a} \leq 300 \mathrm{~W} /\left(\mathrm{m}^{2} \mathrm{~K}\right)
\end{aligned}
$$

When operating the heat exchanger in a wide range of loads, the flow regime inside the tubes can be laminar, transitional or turbulent.

The heat transfer coefficient for the laminar flow on the waterside depends on the assumed boundary condition on the tube surface. It is possible to set a constant tube wall temperature or a constant heat flux. In the case of tubular cross-flow heat exchangers, better compatibility with experimental results was obtained assuming a constant heat flux at the inner surface of the tubes. Fluid temperature variations in the tubular crossflow heat exchanger are similar to changes in fluid temperatures that occur in counter-flow heat exchangers. The difference between the temperatures of both fluids is almost constant over the length of the entire heat exchanger. It can, therefore, be assumed that the heat flux at the inner surface of the tubes is constant.

\subsection{Air-side heat transfer correlation}

The Nusselt number on the air side was assumed in the following form

$$
\mathrm{Nu}_{a}=x_{1} \operatorname{Re}_{a}^{x_{2}} \operatorname{Pr}_{a}^{1 / 3} \quad 225 \leq \mathrm{Re}_{a} \leq 560
$$

where $x_{1}=0.5012$ and $x_{2}=0.4137$ are the parameters, which were determined based on the 70 experimental data sets. The hydraulic diameter on the air side of the investigated heat exchanger was $d_{a}=1.95 \mathrm{~mm}$. The formula proposed by Kays and London was used [1] to calculate the diameter $d_{a}$. The air-side Reynolds number was defined as $\operatorname{Re}_{a}=w_{\max } / v_{a}$, where $w_{\max }$ is the air velocity in the minimum free flow area. The maximum air velocity $w_{\max }$ occurring within the in-line tube rows is

$$
w_{\max }=\frac{s p_{1}}{\left(s-\delta_{f}\right)\left(p_{1}-d_{o}\right)} \frac{\bar{T}_{a m}+273}{T_{a m}^{\prime}+273} w_{0}
$$

where $w_{0}$ is the air velocity upstream of the heat exchanger. The tubes in the radiator were arranged inline. Thus, $w_{\max }$ was the air velocity in the narrowest 
cross-section between two neighboring tubes located in the same row. All physical air properties in Eq. (28) were evaluated at the average temperature $\bar{T}_{a m}=\left(T_{a m}^{\prime}+T_{a m}^{\prime \prime}\right) / 2$.

\subsection{Liquid-side heat transfer correlation}

In this section, heat transfer correlations for laminar flow as well as for transition and turbulent flow in tubes used in the mathematical model of the exchanger are presented. The average Nusselt number $\mathrm{Nu}_{m, q}$ for hydraulically and thermally developing laminar fluid flow in a tube with the uniform wall heat flux, which usually occurs in heat exchangers was used. The following formula recommended by the VDI Heat Atlas [7] was applied

$$
\begin{aligned}
& \mathrm{Nu}_{m, q}= \\
& =\left[\mathrm{Nu}_{m, q, 1}^{3}+0.6^{3}+\left(\mathrm{Nu}_{m, q, 2}-0.6\right)^{3}+\mathrm{Nu}_{m, q, 3}^{3}\right]^{1 / 3} \\
& \operatorname{Re}_{w} \leq \operatorname{Re}_{w, t r b}
\end{aligned}
$$

The limit value of the Reynolds number $\operatorname{Re}_{w, t r b}$, in which the laminar flow ends, and the transitional starts, is usually taken as 2300 [7] or 2100 [14-15]. However, recent experimental studies [10-11] show that the limit value of the Reynolds number $\operatorname{Re}_{w, t r b}$ is influenced by the type and shape of the inlet to the tube.

The symbol $\mathrm{Nu}_{m, q, 1}$ in Eq. (29) denotes the mean Nusselt number for hydrodynamically and thermally fully developed flow

$$
\mathrm{Nu}_{m, q, 1}=\frac{48}{11}=4.364, \operatorname{Re}_{w} \leq \operatorname{Re}_{w, t r b}
$$

The Lévêque solution [16] $\mathrm{Nu}_{m, q, 2}$ denotes the mean Nusselt number for hydrodynamically and thermally fully developed flow over the plate with a linear temperature profile in the fluid and constant heat flux at the wall surface

$$
\begin{aligned}
& \mathrm{Nu}_{\mathrm{m}, \mathrm{q}, 2}=3^{1 / 3} \Gamma(2 / 3)\left(\operatorname{Re}_{w} \operatorname{Pr}_{w} \frac{d_{i n}}{L}\right)^{1 / 3}= \\
& 1.9530\left(\operatorname{Re}_{w} \operatorname{Pr}_{w} \frac{d_{i n}}{L}\right)^{1 / 3}, \quad \operatorname{Re}_{w} \leq \operatorname{Re}_{w, t r b}
\end{aligned}
$$

Eq. (31) was derived by Lévêque [16] using the local Nusselt number for small values of the parameter $\left(x / d_{i n}\right) /\left(\operatorname{Re}_{w} \operatorname{Pr}_{w}\right)$, where $x$ is the distance from the tube inlet.

The Nusselt number $\mathrm{Nu}_{m, q, 3}$ appearing in the correlation developed for a tube with a constant wall heat flux is given by

$$
\begin{aligned}
& \mathrm{Nu}_{m, q, 3}=0.924 \operatorname{Pr}_{w}^{1 / 3}\left(\operatorname{Re}_{w} \frac{d_{i n}}{L}\right)^{1 / 2} \\
& \operatorname{Re}_{w} \leq \operatorname{Re}_{w, t r b}
\end{aligned}
$$

The relationship (32) was obtained by an approximation of Nusselt numbers obtained from a numerical solution of the momentum and energy conservation equations assuming a uniform velocity and temperature profiles at the inlet of the tube.
Taler [8] determined the Nusselt number for the turbulent flow in the tube as a function of Prandtl and Reynolds numbers by integrating the energy conservation equation assuming a radial velocity distribution determined experimentally. Using the Nusselt number values obtained by Taler [8], the correlation for transitional and turbulent flow on the water-side was found by the method of least squares. The friction factor $\xi_{w}$ was evaluated using the explicit relationship proposed by Taler [12] for turbulent flow regime. In this paper, the relationship proposed by Taler [8] was generalized to the following form

$$
\begin{aligned}
& \mathrm{Nu}_{w}=\mathrm{Nu}_{m, q}\left(\operatorname{Re}_{w, t r b}\right)+ \\
& +\frac{\frac{\xi_{w}}{8}\left(\operatorname{Re}_{w}-\operatorname{Re}_{w, t r b}\right) \operatorname{Pr}_{w}^{1.008}}{1.084+12.4 \sqrt{\frac{\xi_{w}}{8}}\left(\operatorname{Pr}_{w}^{2 / 3}-1\right)} \times \\
& {\left[1+\left(\frac{d_{i n}}{L}\right)^{2 / 3}\right],} \\
& \operatorname{Re}_{w, t r b} \leq \operatorname{Re}_{w} \leq 10^{6} \\
& 0.1 \leq \operatorname{Pr}_{w} \leq 1000, \frac{d_{i n}}{L} \leq 1
\end{aligned}
$$

The friction factor in Eq. (36) is given by the following relationships

- turbulent flow regime [12]

$$
\begin{aligned}
& \xi_{w}=\left(1.2776 \log \operatorname{Re}_{w}-0.406\right)^{-2.246} \\
& 3,000 \leq \operatorname{Re}_{w} \leq 10^{6}
\end{aligned}
$$

- transitional flow regime

$$
\begin{aligned}
& \xi_{w}=0.030476+1.45216 \cdot 10^{-5}\left(\operatorname{Re}_{w}-2100\right) \\
& 2.1 \cdot 10^{3} \leq \operatorname{Re}_{w} \leq 3 \cdot 10^{3}
\end{aligned}
$$

The formula (35) for the friction factor results from linear interpolation between $\xi_{w}=64 / \mathrm{Re}_{w}$ for laminar flow at $\mathrm{Re}_{w}=2100$ and turbulent friction factor given by Eq.(34) at $\operatorname{Re}_{w}=3000$.

The water-side Reynolds number $\operatorname{Re}_{w}=w_{w} d_{i n} / v_{w}$ is based on the inner diameter of the circular tube.

The inner diameter of the tubes was $d_{i n}=6.2 \mathrm{~mm}$. The physical properties of the water were determined at the mean temperature $\bar{T}_{w}=\left(T_{w}^{\prime}+T_{w}^{\prime \prime}\right) / 2$.

In the relationship (35) there is a Reynolds number $\mathrm{Re}_{w, t r b}$, at which the transitional flow begins. It was assumed that $\operatorname{Re}_{w, t r b}=2100$. The heat transfer correlation (33) can also be used when the transitional flow regime starts at other values of the Reynolds number [10-11]. In heat exchangers, the influence of free convection inside tubes is negligibly small. Natural convection in horizontal pipes occurs due to the temperature difference of the liquid inside the pipe. The temperature of the fluid in the central part of the tube cross-section is different than near its inner surface. The formation of natural convection is favored by the large diameter and length of the pipe and the high heat flux at the inner surface of the pipe. In heat exchangers, there are usually several passes. Between two neighboring passes, there are reversible chambers or bends, in which the fluid is 
intensively stirred. This, in turn, equalizes the temperature distribution inside the cross-sections of the tubes. At the inlet to each pass, the fluid temperature is almost uniform. The ratio of the length of pipes to their diameters is not very high in heat exchangers. Therefore, there are no conditions to create a large difference in fluid temperature inside the cross-section of the heat exchanger tubes, contributing to the formation of natural convection. For this reason, in the heat transfer correlations (33) and (36) intended for use in heat exchangers, natural convection is omitted.

The water-side correlation $\mathrm{Nu}_{w}=f\left(\mathrm{Re}_{w}, \operatorname{Pr}_{w}\right)$ was assumed for the investigated heat exchanger in the form similar to the correlation (36) valid for flow in straight tubes

$$
\begin{aligned}
& \mathrm{Nu}_{w}=x_{3}+ \\
& +\frac{\frac{\xi}{8}\left(\operatorname{Re}_{w}-\operatorname{Re}_{w, t r b}\right) \operatorname{Pr}_{w}^{1.008}}{1.084+12.4 \sqrt{\frac{\xi}{8}}\left(\operatorname{Pr}_{w}^{2 / 3}-1\right)} \times\left[1+\left(\frac{d_{i n}}{L}\right)^{2 / 3}\right], \\
& 2100 \leq \operatorname{Re}_{w} \leq 18000, \quad 2.6 \leq \operatorname{Pr}_{w} \leq 3.9, \\
& \frac{d_{\text {in }}}{L}=\frac{6.2}{520}
\end{aligned}
$$

The friction factor in the correlation (36) is given by the formulas (34) and (35). The calculations were carried out for $\operatorname{Re}_{w, t r b}=2100$. The unknown parameter $x_{3}$ in formula (36) corresponds to the average Nusselt number $\mathrm{Nu}_{m, q}$ in Eq. (33) which was $\left.\mathrm{Nu}_{m, q}\right|_{\mathbf{R e}_{\text {e }}, t r=2100}=9.62$ considering that the average Prandtl number for 70 data series was $\operatorname{Pr}_{w}=3.244$. The parameter $x_{3}=10.4923$ was determined by the least squares method using 70 experimental data sets.

\section{Experimental validation of the mathematical model of the heat exchanger at low loads}

The heat flow rate $\dot{Q}_{w, c a l c}$ transferred from the water to air was calculated as follows

$$
\dot{Q}_{w, \text { calc }}=\dot{V}_{w} \rho_{w}\left(T_{w}^{\prime}\right) \bar{c}_{w}\left(T_{w}^{\prime}-T_{w}^{\prime \prime}\right),
$$

where $\dot{V}_{w}$ - volume flow rate measured at the inlet of the heat exchanger, $T_{w}^{\prime}$-measured temperature at the inlet of the heat exchanger, $T_{w}^{\prime \prime}$ - calculated temperature at the outlet of the heat exchanger, $\bar{c}_{w}$-mean specific heat capacity in the range from $T_{w}^{\prime \prime}$ to $T_{w}^{\prime}$.

The temperature $T_{w}^{\prime \prime}$ was evaluated using the formula (15). The air-side Nusselt $\mathrm{Nu}_{a}$ number was calculated using the correlation (27) and the water-side Nusselt number $\mathrm{Nu}_{w}$ was obtained from the empirical correlation (36) or the theoretical formula (33). If the Reynolds number $\mathbf{R e}_{w}$ is less than 2100 , the water-side heat transfer coefficient was calculated using the relationship (29). The measured volumetric flow rate $\dot{V}_{w}$ at the inlet

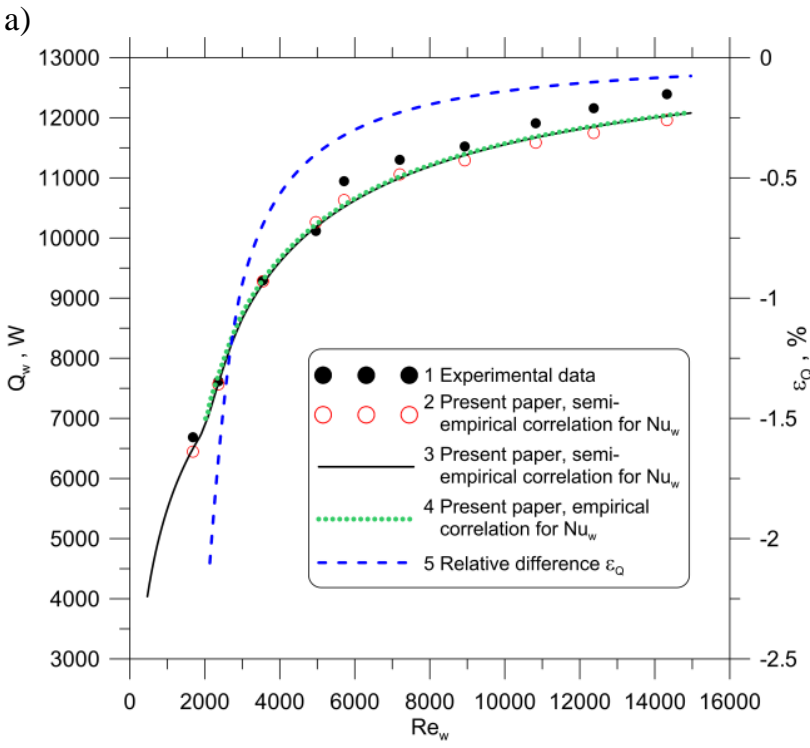

b)

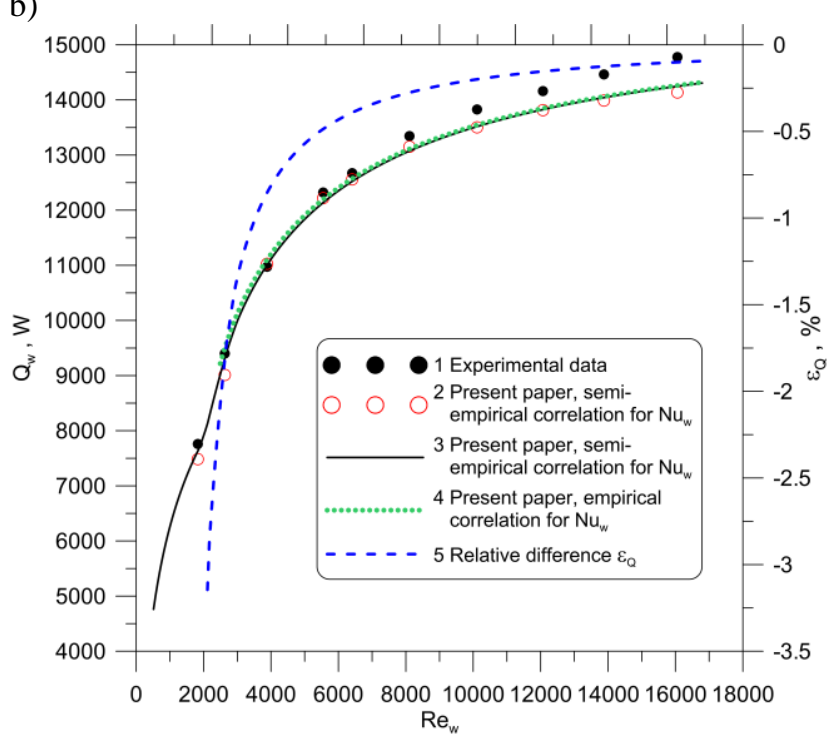

Fig. 3. Comparison of the heat flow rate determined experimentally with the heat flow rate obtained using P-NTU method in the Reynolds number range $500 \leq \mathrm{Re}_{w} \leq 18000$; a) $\left.\bar{w}_{0}=2.27 \mathrm{~m} / \mathrm{s}, \bar{T}_{a m}=8.78^{\circ} \mathrm{C}, \bar{T}_{w}^{\prime}=61.70^{\circ} \mathrm{C} ; \mathrm{b}\right) \bar{w}_{0}=2.27$ $\mathrm{m} / \mathrm{s}, \bar{T}_{a m}=8.24^{\circ} \mathrm{C}, \bar{T}_{w}^{\prime}=70.56^{\circ} \mathrm{C} ; 1-$ heat flow rate $\dot{Q}_{w, \exp }$ determined experimentally, 2 - heat flow rate $\dot{Q}_{w, \text { calc }}$ calculated using the P-NTU method with theoretical relationship (33) for $\mathrm{Nu}_{w}, 3$ - heat flow rate $\dot{Q}_{3}=\dot{Q}_{w, \text { calc }}$ calculated using the P-NTU method and theoretical relationship (33) for $\mathrm{Nu}_{w}$ using the mean values of measured quantities $\bar{w}_{0}, \bar{T}_{a m}^{\prime}, \bar{T}_{w}^{\prime}$, and $\left.\mathrm{Nu}_{m, q}\right|_{\operatorname{Re}_{w, t r b 2100}}=9.62,4$ - heat flow rate $\dot{Q}_{4}=\dot{Q}_{w, \text { calc }}$ calculated using the P-NTU method and empirical relationship (36) for $\mathrm{Nu}_{w}$ using the mean values of measured quantities $\bar{w}_{0}, \bar{T}_{a m}^{\prime}, \bar{T}_{w}^{\prime}$, and $x_{3}=10.49,5$ - relative difference $\varepsilon_{Q}$ between $\dot{Q}_{3}$ and $\dot{Q}_{4}\left(\varepsilon_{Q}=100\left(\dot{Q}_{3}-\dot{Q}_{4}\right) / \dot{Q}_{3}\right)$. Then the mean values $\bar{w}_{0}, \bar{T}_{a m}^{\prime}$, and $\bar{T}_{w}^{\prime}$ from the measurement series were calculated and used in the P-NTU method to determine $\dot{Q}_{w, \text { calc }}$ as a function of the volumetric flow rate $\dot{V}_{w}$. 
of the heat exchanger, as well as the measured inlet water temperature $T_{w}^{\prime}$ and the outlet temperature of the water $T_{w}^{\prime \prime}$, were used for calculating the heat flow rate $\dot{Q}_{w, \exp }$

$$
\dot{Q}_{w, \exp }=\dot{V}_{w} \rho_{w}\left(T_{w}^{\prime}\right) \bar{c}_{w}\left[T_{w}^{\prime}-\left(T_{w}^{\prime \prime}\right)^{\text {meas }}\right]
$$

where: $\rho_{w}$-water density, $\bar{c}_{w}$ - mean specific heat of the water between $T_{w}^{\prime \prime}$ and $T_{w}^{\prime}$.

The relative difference $\varepsilon_{Q}$ between the calculated heat flow rate $\dot{Q}_{w, \text { calc }}$ and the heat flow rate $\dot{Q}_{w, \text { exp }}$ was determined as follows

$$
\varepsilon_{Q}=\frac{\dot{Q}_{w, \text { calc }}-\dot{Q}_{w, \text { exp }}}{\dot{Q}_{w, \text { calc }}} \cdot 100 \%
$$

The comparisons of the calculated and measured heat flow rates are shown in Fig. 3.

The relative difference values $\varepsilon_{Q}$ shown in Fig. 3 were calculated for each measurement series. The heat flow rate $\dot{Q}_{w, \text { calc }}$ in Eq. (39) was calculated using the PNTU method, in which the input data was the air velocity $w_{0}$, the volume flow rate $\dot{V}_{w}$, the air temperature $T_{a m}^{\prime}$ and water temperature $T_{w}^{\prime}$. The heat flow rate $\dot{Q}_{w, \text { calc }}$ is indicated in Figure 3 with empty circles (entry no. 2).

The $\dot{Q}_{w, \text { calc }}$ values were evaluated using theoretical correlation (33) for $\mathrm{Nu}_{w}$ (solid line in Figure 3, entry no. 3 ) and empirical correlation (36) (point curve in Figure 3 , entry no. 4) and used for determining $\varepsilon_{Q}$ by Eq. (39) (dashed line in Figure 3, entry no. 5).

An inspection of the results presented in Figure 3, shows that the application of the semi-empirical correlation (33) [9] for the water-side Nusselt number in transitional and turbulent flow regime gives very satisfactory agreement between calculated and experimental values. Also, the differences between calculated and experimentally determined heat flow rates in laminar flow range are small (Fig. 3).

Many other experimental tests were carried out for various air velocities and water flow rates. An excellent compatibility between measured and calculated heat flow rates was achieved for all data sets.

\section{Conclusions}

New theoretical heat transfer correlation for calculating the water-side Nusselt number in transition and turbulent flow regime was proposed and validated experimentally. Also, empirical heat transfer correlations on the water and air side were parallelly determined. A new formula for the friction factor in the transitional flow regime that is needed to calculate the water-side Nusselt number was proposed. The friction factor in the transitional region $\mathbf{R e}_{w, t r b} \leq \mathbf{R e}_{w} \leq \mathbf{R e}_{w, t r e}$ was determined by linear interpolation between the friction factors at $\operatorname{Re}_{w}$
$=\operatorname{Re}_{w, t r b}$ and $\operatorname{Re}_{w}=\operatorname{Re}_{w, t r e}$. It should be emphasized that proposed semi-empirical water-side heat transfer correlation may be used for different, experimentally determined values of $\mathrm{Re}_{w, t r b}$ and $\mathrm{Re}_{w, t r e}$, not only for $\operatorname{Re}_{w, t r b}=2100$ and $\operatorname{Re}_{w, t r e}=3000$. The linear interpolation of the friction factor in the transitional flow regime requires the knowledge of $\mathrm{Re}_{w, t r b}$ and $\mathrm{Re}_{w, \text { tre }}$. The proposed theoretical and empirical water-side correlations ensure the continuity of the Nusselt number at the transition from laminar to turbulent flow. The heat flow rates calculated using the P-NTU method with new heat transfer correlations agreed very well with the heat flow rates determined experimentally. The new waterside relationships for the friction factor and Nusselt number in transitional and turbulent flow regime proposed in the paper can be used in a wide range of load changes. The liquid flow regime in tubes can vary from laminar through transitional to turbulent, and vice versa. The heat transfer coefficient at the tube inner surface is a continuous function of the Reynolds number without sudden variations during the change of the laminar to transition or transition to the turbulent flow regime. Due to the continuity of variations in the waterside heat transfer coefficient, the fluid temperature at the outlet of the heat exchanger or the heat flow rate transferred from hot to the cold fluid can be adjusted smoothly by changing the rotational speed of the pump, i.e., by changing the volume flow rate of the liquid.

\section{References}

1. W.M. Kays, A.L. London, Compact Heat Exchangers, $3^{\text {rd }}$ ed. (Krieger, Malabar, Florida, USA, 1998)

2. S. Kakaç, H. Liu, A. Pramuanjaroenkij, Heat Exchangers. Selection, Rating, and Thermal Design, $3^{\text {rd }}$ ed. (CRC-Taylor \& Francis Group, Boca Raton, USA, 2012)

3. R.K. Shah, D.P. Sekulić, Fundamentals of Heat Exchanger Design (Wiley, Hoboken, USA, 2003)

4. T. Kuppan, Heat Exchanger Design Handbook, 2nd ed. (CRC-Taylor and Francis Group, Boca Raton, USA, 2013)

5. D. Taler, Numerical Modeling and Experimental Testing of Heat Exchangers (Springer International Publishing, Berlin-Heidelberg, 2019)

6. D. Taler, J. Therm. Sci. 26, 339-348, (2017)

7. V. Gnielinski, VDI Heat Atlas, Chapter G1 (Springer-Vieweg, Berlin-Heidelberg, 2013)

8. D. Taler, Int. J. Therm. Sci. 108, 108-122, (2016)

9. D. Taler, Energy Convers. Manage. 159, 212-243, (2018) 212-243

10. A.J. Ghajar, L.M. Tam,_Exp. Therm. Fluid Sci. 8, 79-90, (1994)

11. J.P. Meyer, M. Everts, Int. J. Heat Mass Transf. 117, 1251-1273, (2018)

12. D. Taler, Int. J. Therm. Sci. 105, 109-122, (2016)

13. D. Taler, Heat Mass Transfer 49, 1125-1139, (2013) 
14. S.W. Churchill, Chem. Eng. 84, 91-92, (1977)

15. D.C. Rennels, H.M. Hudson, Pipe Flow. A Practical and Comprehensive Guide (AIChE-Wiley, Hoboken, 2012)

16. M.A. Lévêque, Ann. Mines, Memoires, Series 1213, 201-299, 305-362, 381-415. (1928) 